\title{
Key Aspects of Leisure Experiences in Protected Wilderness Areas: Notions of Nature, Senses of Place and Perceived Benefits
}

\author{
Andrés Ried ${ }^{1, *(1)}$, María Jesús Monteagudo ${ }^{2}$, Pelayo Benavides ${ }^{1}$, Anne Le Bon ${ }^{1}$, \\ Stephanie Carmody ${ }^{1}$ and Rodrigo Santos ${ }^{1}$ \\ 1 Center for Local Development (CEDEL), Pontificia Universidad Católica de Chile, Villarrica 493000, Chile; \\ sbenavme@uc.cl (P.B.); annelebon1@gmail.com (A.L.B.); stefcarmody@gmail.com (S.C.); rlsantos@uc.cl (R.S.) \\ 2 Leisure Studies Institute, Faculty of Social and Human Sciences. University of Deusto, 24, \\ 48007 Bilbao, Spain; mjmonte@deusto.es \\ * Correspondence: rried@uc.cl
}

Received: 28 February 2020; Accepted: 3 April 2020; Published: 16 April 2020

check for updates

\begin{abstract}
The main objective of this research was to contribute to the understanding of leisure experiences in protected wilderness areas. This was pursued through the interpretation and analysis of three variables; the personal notion of "Nature", perception of benefits, and senses of place put forward by resident and non-resident visitors to three protected wilderness areas in southern Chile. Through a post hoc qualitative, in-depth interview with 36 subjects, connections between the aforementioned variables were established. Among the results, the strength with which the romantic notion of Nature appears linked with leisure experiences was highlighted. With the latter, leisure experiences in protected wilderness areas were identified as the generators of "benefits" and "sense of place". Finally, four key dimensions of leisure experiences in protected wilderness areas emerged: transcendence, perception of well-being, connection and environmental awareness.
\end{abstract}

Keywords: nature; leisure; sense of place; benefits; sustainable beliefs

\section{Introduction}

This article presents the results of an investigation that examined leisure experiences in wilderness protected areas (WPA) and the role played in them by the personal notion of Nature, the perception of benefits, and the sense of place. Leisure in wilderness areas is understood as a voluntary, autotelic, and libertarian experience, which develops in a space perceived as natural, through a deep interaction between the surroundings and the people, which results in intrinsic satisfaction and directly contributes to the well-being and development of people and the natural environment [1]. We believe that wilderness areas, which are understood as territories with scenic and recreational value destined to the conservation of biodiversity, contain their own qualities, that is to say, ontological qualities, making them a privileged space for leisure. This is due to their potential to either provide intrinsic satisfactory experiences, or to provide multiple benefits, reveal emotions, feelings [2], satisfy human needs, and provoke an encounter with "primal" instincts. Theoretically, the potential of protected wilderness areas with regard to leisure and human development would imply certain advantages over artificial environments with human predominance [1]. In this respect, protected wilderness areas provide exceptional conditions for the satisfaction of other human needs (such as understanding, subsistence, identity, and affection). Therefore, the study of leisure experiences in wilderness protected areas (LEWPA) considers the complexity of the relationship of human beings, nature, and leisure, making it necessary to expand the traditional view on how to investigate and understand the interaction between people and natural settings. 


\subsection{Nature: History of the Concept and Relationship with Wilderness Protected Areas (WPA)}

The concept of "Nature" is highly polysemic, and given its entanglement with leisure experiences in WPA, it is necessary to critically review structural and structuring aspects defined by its history. According to Milton [3], "Nature" can refer "to that part of the environment that is separated from human activity" (p. 83); "to a scheme of things that encompasses everything and includes human beings along with everything else" (p. 83), and sometimes "to a quality of human beings and other beings that is assumed to be innate rather than acquired" (p. 83). In this article we refer to the first two meanings, writing Nature with a capital " $\mathrm{N}$ " to differentiate it from its original meaning in Greek (physis), contained in the third meaning.

The understanding of "Nature" as a complete system did not influence the popular European vision for a long time. In fact, in the Aristotelian framework, humanity was part of Nature, "without dissociating itself from an eternal cosmos" [4] (p. 66) that could be understood through certain laws, precisely because we were part of it. However, Christianity and "its dualistic idea of the transcendence of humanity and of a universe created out of nothing by the will of God" [4] (p. 66) widened the gap between humanity and the surrounding world, although without a radical separation [5] (p. 65). The historical European notion of an external and "readable" natural kingdom is relevant to the WPA, as environmental knowledge is assumed to be based on privileged access to Nature. Thus, in the European Middle Ages, Nature was likened to a book in which one could "decipher the evidence of divine creation" [4] (pp. 66-67). Nature was "universally evident", where all people could see its unity [4] (p. 67); see also [6] (p. 740).

Later on, the medieval European world gave way to a systematic fragmentation and "estrangement" of Nature in the Renaissance with a focus on humanity as the measure of things [5] (p. 65). Subsequently, Nature, as a scientific category and part of the political discourse, was founded on the intellectual environment of French illustration, finding its modern expression in the late 18th century [7] (p. 13). Alexander von Humboldt's insights, as the creator of the notion of the "web of life", are crucial for current understandings of Nature [8] (p. 87). Johann Wolfgang von Goethe and German Romanticism profoundly influenced his vision, valuing imagination, aesthetics, and feelings in our understanding of the "natural world" [8] (pp. 29-38). This vision of the "internal connections of natural forces" (Wulf 2016: 133) impacted crucial authors in biology (e.g., Charles Darwin, Ernst Haeckel) and more broadly on important authors in the conservation movement (e.g., H.D. Thoreau, George P. Marsh, John Muir) [8] (pp. 217-334). To some extent, this Humboldtian concept of Nature gave scientific support to the establishment of protected areas in the world. As West et al. [9] explain, these types of areas "constitute a way of seeing, understanding, and (re)producing the world. As such, they are places rich in production and social interaction" (252). These areas embody ways of governing and experiencing parts of the world that are defined as "Nature" and "environment", producing a series of social effects.

The history of WPA is long and diverse, expanding geographically beyond America [10] (pp. 19-21). From a historical review in Western Europe (Williams, 1973; Olwig and Olwig, 1979; Cosgrove, 1984, in [10] (p. 115)), changes generated by the legislation of land ownership and rural capitalism became relevant. Through such changes, the elite's ideals about natural landscapes were founded, sanctioning places where humans and their activities were "out-of-place". These ideals were manifested through the creation of a stark divide between "landscapes of production-set aside for the production of wealth-and landscapes of consumption — set aside for the viewing pleasures of rural elites" [10] (p. 115). Thus, the contemplation of scenic landscapes, Nature, and outdoor leisure activities emerged as a quest of the upper classes, in contrast to direct use of and dependence on "natural resources" for survival. The most widespread Western conservationist values arose from changes in land control and in the ways its proceeds were distributed [10] (p. 115).

While the creation of the first protected areas in the United States (Yosemite State Reserve; Yellowstone National Park) is linked to the writings of Thoreau and Muir, the urban elites of the eastern United States, influenced by the European ideals of "pleasurable views", were the final instigators of 
their creation [10] (p. 115). Thus, Yellowstone became "a model for the creation of virtual landscapes, in the form of theme parks, malls, international hotels, and other spaces designed to present consumers with generic experiences of sanitised histories and landscapes" [9] (p. 258).

Thus, as concept and institution, the "protected area" has become "a new cosmology of the natural", full of positive moral connotations. However, West et al. [9] followed Strathern [11] in asserting that through its creation and implementation, a Nature-Culture dichotomy has been imposed "on places and people where the distinction between nature and culture did not previously exist" (p. 255). Given that from western romantic understanding, Nature and the sociocultural sphere are conceptualized "as extremely opposed entities" [12] (p. 4), it has been assumed that their interaction leads one or the other to be damaged. Consequently, this has promoted the creation of human-free areas, as well as "exclusive zoning" practices [12] (p. 4). This operation has resulted in these areas being constantly described as human-free, in response to the romantic ideal from which they were originally formulated [13]. Thus, expectations regarding these areas, as well as leisure experiences reported in them, are interwoven with the conceptualization of non-anthropic and pristine Nature, which also emerges in the meaning given to these places and experiences.

\subsection{The Benefits of Leisure in Protected Wilderness Areas (WPA)}

One of the main focuses of interest of Leisure Studies specialized in protected wilderness areas has been the broad spectrum of benefits that contact with nature can provide [1,14-18]. Through these, people satisfy basic psychological needs that may not be met in contexts and moments of non-leisure [19].

In the specialized literature, the study of leisure benefits has been traditionally approached in terms of "expectations" about the positive returns to be obtained from leisure experiences or as "consequences" of the latter, analyzing positive effects of such experiences in depth. This study understands the concept of "benefit" not only as the traditional notion of "change that is perceived as advantageous, an improvement in some aspect that can favour the person, group, society, or any other entity" [20] (p. 4), but also as prevention and/or maintenance of a certain situation or condition and the enjoyment of a satisfactory psychological experience with value in itself [20].

The best documented benefits of leisure in natural spaces may be described as physiological [21,22], psychological [23-26], and relational [27]. However, there is abundant literature on other taxonomies of benefits: spiritual [28], environmental [16], economic [14,16], or educational [29], for example.

Apart from semantics, the main advances in the study of leisure benefits in wilderness protected areas can be seen in two main areas. On the one hand, most research has focused for decades on establishing the conditions of proximity to, and frequency of, contacts with natural spaces, necessary to maximize the returns derived from person-nature interactions $[17,20,24,26]$. On the other hand, and in parallel, literature has increasingly specialized in the benefits of visits to specific natural areas, far from cities, such as WPA. This increase coincides with a growing interest in the quality of such spaces [30] and their incidence in the perception of their benefits $[1,31]$. Quality refers to the biological attributes of spaces: the presence of wildlife, biodiversity of the area, scenic beauty or pristine condition [15,32,33]. Some studies suggest that these attributes especially favor mental health through the perception of psychological benefits [34]. Underlying this premise is the idea that perceived benefit types depend, among other aspects, on the type of natural spaces in which leisure experiences take place $[31,35,36]$.

On the other hand, research on the benefits of leisure in WPA has recently focused on clarifying the mechanisms that promote the perception of such benefits. Firstly, this implies understanding the processes that explain the positive returns from contact with Nature in leisure situations. The focus is centered on the identification of the intervening variables that modulate, by facilitating or inhibiting, the perception of benefits in natural spaces [31]. These include socio-demographic variables, such as age, gender, and social or economic status [37,38], and other variables such as the importance attributed to Nature in mediating the perception of benefits [31]. It is possible to think that the notion of Nature can be a central variable when explaining the values and attitudes that we harbor towards natural 
spaces, as well as the type of leisure experiences we have in them and the benefits that this contact generates. If this is so, it provides justification for studying the role played by the notion of Nature that each person holds and the meaning this gives to their leisure experiences and to the wild spaces themselves. In fact, numerous studies have focused their interest on the identification of such meanings, under the concept of "sense of place", understood as a specific type of benefit which denotes a deep connection or emotional bond with the natural space that provides the leisure experience [39-42].

The next section delves into the concept of sense of place, and its importance in understanding the significance that LEWPA can have in the life of their protagonists.

\subsection{Sense of Place and Leisure Experience in WPA}

As a complex and elusive concept, "sense of place" is one of the most attractive and innovative ways of understanding the connection between human beings and Nature [40,43-45]. In recent decades, the notion of sense of place has consolidated the idea that the bond between Nature and human beings depends primarily on the interaction between the person (history, identity, feelings, emotions, meanings, and experiences) and the physical environment or place [40,46-48]. This view incorporates interactive aspects of a subjective, symbolic, and social nature, linked to the motivations, preferences, and identities that arise or consolidate from experiences with — and in — the natural world [45,49-51].

The basis of this idea is the process by which a physical space is transformed into a place, that is, when, due to a personal and/or collective experience, the space acquires significance and meaning, generating processes of identity and identification $[43,45,52,53]$. The "experience" occupies a central position in the definition of sense of place and the construction of personal and territorial identity $[1,41,47,50,54-56]$. Through their experiences, people form emotional and affective bonds with the natural places they visit [57]. In this way, these places become special, valued as favorites and protected from damage or destruction by those who identify them as such [58].

The natural places most frequently identified in the literature as special include bodies of water such as rivers, lakes, waterfalls, and oceans [15], forests [34], and other spaces, such as mountain peaks [32]. Certain places are also considered special because of the biodiversity they contain. From the interaction with these special places, feelings and emotions arise, such as: freedom from daily routine; connection with the universe or other entities according to beliefs; absorption; and significance of the present moment [33].

Roggenbuck and Driver [59] suggest that the sense of place can be understood as a new class of benefit. Similarly, specialized literature has ratified the sense of place as a new type of benefit that WPA provide to people $[1,42]$ and that can be understood as a cultural service of ecosystems $[16,60,61]$. This approach emphasizes the importance of the deep emotional ties that sense of place entails and its impact on identity processes, appropriation of places, and environmental awareness, which, until recently, had been underestimated in the scientific literature [62].

Since the WPA emerge in the scientific literature as privileged spaces for leisure experiences and the generation of sense of place, this article raises three primary objectives, each associated with different questions: (1) Contribute to understanding of leisure experiences in WPA. Consistent with this objective, we seek to answer the following question: What types of benefits do people perceive derived from their leisure experiences in WPA? (2) Know the sense of place associated with WPA, based on leisure experiences in these spaces. Linked to this second objective, the following question is posed. What kind of bonds with the place do people who visit the WPA develop? and (3) Understand the notion or notions of Nature associated with leisure experiences in WPA. The questions to consider are the following: what notion or notions of Nature prevail among WPA visitors? How do these notions interact with their leisure experiences, perceived benefits, and the sense of place they develop?

\section{Materials and Methods}

This research uses a qualitative methodological design to understand LEWPA in all of their complexity. Leisure is approached from a psycho-social perspective, based on the concept that the 
leisure activity is determined by the interrelationships between the subjective experience of individuals and the physical and social environment where such experience takes place. This approach assumes that, in order to respond to the research objectives, it is necessary to understand the meanings and significance that people attribute to their leisure experiences, to the places where they occur, and to the benefits they perceive. In-depth semi-structured interviews were considered the most suitable way to gather people's perceptions, feelings, and opinions about their leisure experiences. The experience is seen as an integrated whole, rather than the sum of its parts [62-64]. Although the ways of perceiving Nature can be identified and categorized, leisure experience in natural spaces "is much more than a visual and aesthetic preference, upon which it is not easy to formulate characterisations in terms of concepts and conventional scientific methods" [65] (p. 85).

\subsection{Area of Study}

This research focused on visitors to the Villarrica, Huerquehue, and Conguillio National Parks in the Araucanía Region, Chile. These protected wilderness areas have some characteristics that make them ideal for this research. They have high visitation rates, receiving diverse visitors (international and national tourists, local residents and enthusiasts) and they have exceptional natural heritage (volcanoes, glaciers, ancient forests, variety of recreational services), with indigenous communities neighboring the parks) (Appendix B).

\subsection{Instrument}

The semi-structured in-depth interview allows a rich and direct exploration of the perceptions and attributions of meaning that people in the sample give to their leisure experiences in WPA. The interview used in this study was constructed and validated by Ried [1], considering specialized scientific literature on leisure preferences and benefits [14]; special places [65]; and place attachment [48,66,67]. It was composed of 48 questions divided into different thematic blocks; however, for the purposes of this article, only aspects related to LEWPA will be addressed: meanings given to Nature; perception of leisure benefits in WPA; and the sense attributed to such places. The methods were approved by the ethical committee of the Pontificia Universidad Católica de Chile dated October 21, 2015 with code 15049001.

\subsection{Sample}

The interview was applied ex post to a non-random intentional sample of 36 people (12 in each WPA) who had visited at least one of three Protected Wilderness Areas (WPA) (Conguillio, Villarrica, and Huerquehue National Parks). More specifically, the sample was formed by four groups, with specific profiles defined by the study: residents of the neighboring districts of each protected wilderness area who came only to spend a day in the park, residents who stayed for several days camping, visitors who came only to spend a day in the park, and visitors who stayed for several days camping. To identify these groups, residents and visitors were contacted during fieldwork during the months of January and February 2017. Then, through the snowball method, the other subjects in the sample were contacted, by information provided by participants intercepted in fieldwork who shared their same profile; thus, researchers chose an interviewee who met the criteria considered an ideal type of subject for the sample. This participant suggested another person, who in their opinion met the pre-established requirements [63]. This method maximizes the possibilities of having informants who meet the criteria established by the researcher, in addition to receiving first-hand guidance from the subjects who are considered key to the study (Table A2). The number of interviews analyzed is a result of the saturation and repetitiveness of discourses detected after the application, transcription, and preliminary analysis of the recordings. 


\subsection{Procedure}

The interviews were conducted individually and lasted an average of 40 minutes. The complete transcription of the interviews was done as they were being undertaken, by the research teams, in order to capture information that helped to interpret the data from the start [67]. They were transcribed and analyzed through repeated reading of transcripts [68], in order to obtain a deeper understanding of each text. The interviews were analyzed using the Atlas Ti software version 8.4.24.0, reference number 103865351 that allowed extracting, categorizing, and intertwining segments of data, facilitating the application of the constant comparative method [69]. In principle, each interview was transcribed and then coded, organizing categories by density and relationships, resulting in families related to three main variables: (a) Meanings of Nature; (b) Perceived benefits; and (c) Sense of place and special places. The interview script and its variable can be reviewed in Appendix A. Each family, in turn, is made up of a certain number of codes. These categories and families were analyzed according to their own and specific meanings, as well as their relationship with the other categories and families [63,67]. This analysis was constantly and simultaneously subjected to the final and total understanding of the text and to the consideration of the context where the data were collected. This process is also known as relativization of the data [70]. In turn, these families were represented graphically through hermeneutical maps, which show the relationships between families and codes. The denominations for each family try to respect predominant expressions and concepts in the narratives of the subjects of the study.

No differences were made between visitors to national parks since no substantial differences emerged that contributed to the research objectives. In addition, the set of interviews was considered a single corpus that allowed us to reach a deeper understanding of leisure experiences in the WPA. In our case, the emphasis was focused on understanding the meanings manifested directly by the subjects interviewed.

\section{Results}

This section presents the main results as hermeneutical maps and conceptualizations representing families and their most important interactions for each aspect investigated; i.e., meanings of the notion of Nature, benefits of leisure experience, and sense of place. This section expresses the result of the interpretation of the statements of the people investigated, coded according to terms used by the interviewees themselves.

\subsection{Meanings of the Notion of Nature}

The meanings that respondents attributed to Nature were organized into five thematic families: Source, Connection, Benefits, Sanctuary, and Environmental Consciousness.

The meaning denominated by "Source" is composed of six codes (Origin, Life, Mother, Sustenance, Home, and Holistic) and refers to a conception of Nature as an original entity that sustains human life (and of all other beings) and provides them with tangible (food) and intangible (security) resources. It is the means of sustenance and the home and is related as a holistic system upon which human beings depend and upon which they have an influence: "It is an invaluable resource, for me, in which each being has an importance and a participation in a whole, in a network" (Juan Pablo).

The meaning denominated by "Connection" is composed of six codes (Connection with Nature, Uniqueness, Biophilia, Everyday life, Dependence, and Home) and can refer to a specific milestone resulting from contact with Nature, which makes an experience unique and stimulates reflection about the proximity and affinity towards the natural world. It also emerges as a perceived fundamental need, a lifestyle that justifies even the place of residence of the interviewees: “The colors, the aroma ... If I spend a lot of time in an (urban) place, I feel the need to be surrounded by something green. If I go to Santiago, for example, I escape, even if it is only to a square or a park, I need this connection. To sit on the grass, go barefoot, I need to be in touch with Nature or with water or snow" (Albert). 
The meaning denominated by "Benefits" is composed of five codes (Learning, Escape, Tranquility, Restoration, and Well-being) and refers to a definition of Nature as a provider of certain benefits, especially psychological, that improve the subjective well-being of people. It is also about the learning opportunities that take place in Nature, the sensation of freedom and tranquility that it grants, the physical and mental restoration that can be experienced after having been in Nature, and the perception of well-being and clarity that contact with the natural environment generates: "When walking through the woods or climbing mountains, it definitely changes your brain and makes you think differently and solve many things" (Fernando).

The meaning denominated by "Sanctuary" is composed of seven codes (Divine Creation, Divinity, Church, Respect, Insecurity, Wholeness, and Devotion) and accounts for a sacred conception of Nature: it is a place or an entity that inspires respect and devotion. Many interviewees consider that Nature is a divine creation, or divinity itself, while others consider it a place conducive to spirituality. This sanctification of Nature leads to an attitude of devotion and respect (which in some cases translates into insecurity in the face of the immensity and power of Nature): "To know that there are so many galaxies, that colors and matter exist, that is already a reason for devotion, and then to see it especially organized into life, in that vertex between harmony and chaos, in that tremendous wonderful network which is life itself, I can only feel gratitude" (Aldair).

The meaning denominated by "Environmental" awareness is composed of three codes (Respect and admiration, Pain, and Conservation) and accounts for an attribution of deep admiration for Nature, which tends to translate into "pain" in the face of environmental damage caused by human activity and attitudes-or in conservationist discourses: "I feel Nature's pain. To me Nature is a suffering being, a being of which we are all part, because it is like a living body and we are all involved in it. Then it is this body in which we all breathe, in which we vibrate, in which we all live. And there it is: on its last legs" (Soledad). These discourses suggest a potential trend towards the development of pro-environmental behavior on the part of the study subjects (Figure A2).

\subsection{Perceived Benefits from Leisure Experiences in WPA}

This category consists of seven families that allude to types of benefits, emerging from the analysis of the questions specifically indicated on this variable: (1) Recreational opportunities; (2) Physical benefits; (3) Psychological benefits; (4) Transcendent emotions; (5) Educational benefits; (6) Ecosystem services; and (7) Time travel.

The family denominated by "Recreational opportunities" is made up of three codes: Activities, Scenery, and the Challenge of exploration. The Activities code is related to the possibilities of developing visitors' pastimes, particularly photography, hiking, bird watching, sailing, and camping. In turn, the Scenery code is linked to admiring the aesthetic beauty and being in a physical environment that distinguishes itself from the city where trees, mountains, and bodies of water generally stand out. The Challenge of exploration code alludes to the perception of the discovery of Nature that involves physical and mental challenge and is linked to satisfaction. In this sense, it is the natural space, the natural scenery that stimulates and incites the efforts: "I dared to do it. I dared to do it because I went with my husband: because there is a personal challenge, such as reaching the summit, doing the trekking, where after so many hours of walking and sacrifice there is always a beautiful place to admire, then returning home you feel good, you take on new energies (Macarena)".

The family of "Physical benefits" comprises three codes: Restoration, Health, and Challenge, and refers to the restorative property of the physical qualities of LEWPA. Restoration and physical health codes explicitly emerge as the ability to recover certain physical abilities and qualities from being in the WPA: “(...) to be able to enjoy long hours in this environment. I find that you feel renewed, you rest, and you get energized. There is a physical or health benefit when I go to the hot springs or after a long walk: you feel more agile, healthier" (Mariela). This family also includes the Health code and refers to the quality that the WPA provides as integral health, not only referring to the psychological or physical restoration: "On a physical level, on a psychic level, one recovers energy, gets rid of tensions" 
(Daniela). The Challenge code for this family is linked to the perception of physical efforts that the LEWPA allows; there is a perception that Nature invites you to go beyond bodily limitations: “(...) every time you do a trek, a trail, there is a physical effort behind it, also a mental challenge, and it affects your mood" (Macarena).

The family "Psychological benefits" includes the codes: Restoration, Tranquility, Disconnection, and Well-being. The Restoration code refers to the LEWPA's contribution to reducing stress and recovering from mental fatigue. "To clear your mind, de-stress, see a nice view, leave concrete for a while, all those buildings, all of that. For me it is to get out. If I could live in Nature I would" (Angelo). The codes Tranquility and Disconnection arise from the perception of calm and peace that the WPA grant, contrasting with life in the city; "Being in Nature relaxes you, it clears your mind. There are places that are far from city noise like cars, and so many people talking" (Vicente). The Well-being code brings together concepts that are linked to the sensory perception of the natural world and the emergence of emotions such as joy, gratitude, and individual and family enjoyment. The discourse of feeling good and/or happy is dominant in this family, so the notion of well-being seems to fit correctly in this family. Constance describes the happiness it brings her to take her children to the WPA: "I felt happy to be doing an enriching activity for the children, because usually they are always inside the house, because they have a lot of entertainment inside and are rarely out in Nature and I felt like I was teaching them something" (Constance).

The family "Transcendent emotional benefits" alludes to experiences that are considered as sublime, that allow transcending the material and approaching spiritual and intangible planes. This family is made up of the following codes: Meditation, Spirituality, Personal growth, and Connection with Nature. The benefit of meditation is understood as a state of introspection that is related to self-knowledge and that is facilitated by the WPA. Spirituality appears as the benefit that emerges from perceiving a positive emotion by connecting with other planes (the divine and/or sublime): "It is a way of meeting the creator, I feel that I see God, I really feel him" (Cristian). On the other hand, the Personal growth code refers to the capacity that a transcendent emotion has to generate a change of thought or habit, in this sense it is explicitly perceived as a benefit. The interviewee Javiera explains it as follows: "I believe that each trip, each experience that we have in the parks, changes our way of being, since it makes you grow as a person". The code connected with Nature refers to the feeling expressed by the interviewees of feeling part of the natural world, usually related with the experience of encounters with natural beings (animals, trees): "I was climbing the Llaima volcano and I saw a couple of condors flying just half a meter away (...) How exquisite this connection to see wild birds, the most beautiful bird in this country and right above you! That kind of thing, those experiences maybe, I don't know if they are religious or experiences at a level of total connection" (Natalia). This code in turn contains the perception of uniqueness, a sensation that is reported as total integration with the natural surroundings: "When you are in these wide open places, so full of things that surprise you, that fill you, that revitalize you, you realize that you are part of a whole and you feel small and you feel great" (Soledad).

The family of "Educational benefits" is related to a process that contains, on the one hand, the possibility of learning about some aspect of Nature and, on the other hand, the ability to generate environmental awareness in others (visitors, friends, and family). It is constituted by the following codes: Knowledge-exploration, Teaching-learning, and Environmental awareness. The Knowledge-exploration code refers to the process of discovery in Nature and is narrated in relation to the knowledge of the biodiversity of the WPA- “to learn the species of trees, plants, birds, animals which are seen less and less" (Lilian) - and kindles a fascination in some of the subjects that transform it into their main interest. The Teaching-learning code appears as a somewhat more specific benefit than the previous one. It is interpreted as a pedagogical situation, where there is an educational intent that contains an explicit conservation dimension. Raquel explains it in relation to her daughter: "Now I am here with my daughter, for her to discover, for her to have the corresponding contact with Nature, the care, to teach her all these kinds of things". The environmental awareness code is perceived as a result of the LEWPA that overcomes the cognitive aspect; in addition to knowledge, a perception of 
pro-environmental attitude emerges here that is transferred to everyday life: "I think that every time I visit these places, these Nature sanctuaries (...) I tend to take more care of the environment. I carry this care I have in the park with me to the city" (Lilian).

In the benefits family of ecosystem services, the park is mentioned as a source of sustenance, in particular the provision of water and clean air: "you can breathe pure air here, drink delicious water that springs from the ground here" (Miguel).

The "Time machine" family, refers to the observation that the LEWPA provokes memories of personal experiences or past times in the same context and is made up of the codes memories and timelessness. The family particularly refers to childhood; the interviewee Natalia explicitly says: "The same thing happens to me too. It evokes childhood memories. The first memories one has of outdoor experiences". In some cases people experience chronological time differently, such as the feeling that time passes slower than in cities: "It happens to me in these places, when one is with another person in these places, you can talk about things that you would not talk about in another context. Time is not a problem, it is different" (Vicente) (Figure A3).

\subsection{Sense of Place/Special Places}

Sense of place emerged mainly from questions referring to the identification and description of special places and questions related to attachment and identity in relation to particular places. As a way of provoking the identification of sense of place, participants were asked to identify three special places of the visited park, and they were asked to describe them physically. Subsequently they were asked about the attachment, experiences, memories, and associations that they had with the visited area.

In relation to Sense of Place, seven different interrelated families were identified, representing a sense of particular places visited; they have been ordered as follows: transcendence, subjective well-being, time, connection, awareness, scenery, and subjective discomfort. As seen in Figure A4, the families are linked to the central notion of sense of place of the figure and, in turn, these families are made up of codes that are indicated by the abbreviation SL (sense of place) and its coding. There are codes that feed more than one family, which attests to the complexity of leisure experiences.

The "Transcendent" family emerges in all of the participants' narratives, and the essential codes for this family are: Spiritual sacredness; Humility-gratitude; Amazement (respect-admiration); Uniqueness; and Magic-mystery. Narratives related to the attribution of sacredness of the parks and the perception of magic or mystery, were common and partly explained by the sense of wonder and reverence that the recreational experience in the WPA produces: "I never thought I would see condors so close. Maybe in the distance, but they flew right over us! I felt good because I thought it was magnificent, I felt it as a unique, honorable, very honorable feeling ... it was the best feeling, my seventh chakra is open now!" (Natalia). It is seen how the leisure experience in WPA is considered an experience of a spiritual nature that transcends tangible worlds.

The "Subjective well-being" family is composed of the codes: Escape; Peace-tranquility; and Challenge. In general terms, it refers to the visitors' perception of feelings of well-being and satisfaction. This satisfaction is expressed by the possibility of enjoying the natural world expressed as joy, relaxation, comfort, and an integral perception of well-being that includes different sources of satisfaction. "It was a feeling of happiness, of wanting to contemplate everything, to breathe a lot, to be in touch with Nature" (Fernanda). On the other hand, in this family there are references to the observation that social relations in WPA have a special quality: "I think the best part of this hike was that we did it with friends and with all of our little children, and we made a huge effort to reach the top and obviously they got tired, but it was amazing to walk with young children who also appreciate the forest, the volcano" (Constanza).

The "Time" family considers two dimensions of the concept. On the one hand, its usage in Spanish means "weather", and refers mainly to climatic conditions. Alternatively, it can refer to chronological time. In relation to the weather, this is mentioned as a factor that often leaves an impression, and even fear, but it is not indicated as a negative factor. In some ways, controlled fear provides more 
meaningful experiences for visitors. In relation to chronological time this idea is based on the Time machine code, as interviewees revealed that the park allowed them to travel back in time to their childhood or immemorial times such as the origin of planet Earth: "First we went to the lakes, there was a pond and it was 5 or 6 in the afternoon and we jumped in the water and it was a huge place, the scenery ... it was a lake and in the background there were boulders, at any moment a dinosaur was going to walk past us!" (Vicente).

The family connected with Nature is a complex one that could have also been contained in another category. However, we decided to keep it separated due to the existence of explicit discourses referring to experiences in the parks, which allowed the subjects to feel integrated with the latter. The family consists of the codes: Uniqueness, Accessibility, Restoration, and Connection. Among other aspects, this family highlights the multisensory experience of the parks, contrasting with daily life in cities. The idea of connection is also linked to an experience that is not easy to describe and therefore appears to be close to emotional worlds. This connection also relates to the property of the outdoor leisure experience of providing intrinsic satisfaction, termed in some cases as a happy experience: "I felt full, I felt cheerful, I felt connected to Nature, I felt at peace, and I really felt very good" (Alexander).

The "Awareness" family refers to discourses that address the need to conserve WPA, related with the codes Destruction, Conservation, Protection, and Provider. In this family, the feeling that the WPA provides a last refuge for wildlife and biodiversity generates a positive assessment for the existence of these places, but at the same time, a certain pessimism about the destructive capacity of human beings: "I feel the security of the spaces, being protected, where the explosive growth of cities cannot enter. Since they are building everywhere (...) instead, this space that is protected. I think, well, this is a place that is maintained, preserved, even though this position is a little pessimistic, but its protection gives me peace of mind" (Alicia).

The "Scenery" family apparently has a clear visual aesthetic connotation; however, when interpreting the narratives of the interviewees, specific qualities emerge which strongly connect it with the following family. It is constituted by the codes Forest and ecological diversity, Natural strength, and Aesthetic beauty. This "sense of place" refers to the idea of natural beauty, which is not limited to a visual appreciation (although it is predominant). It also considers elements of appreciation of biodiversity found in the WPA and attribution of an energetic character to scenery elements such as volcanoes, waterfalls, and mountains: "It is a very powerful place, where many energies come together, from the lake, from the trees, from the araucarias, from the old trees, from the woodpeckers that can also be heard and sometimes seen" (Macarena).

The "Subjective discomfort" family sense of place (SL), although not observed at high frequencies and densities, is considered relevant due to the contrast it poses with the almost exclusively positive stories about leisure experiences in WPA. It refers to the negative perceptions, feelings of discomfort and fear experienced in the visit to WPA. It is interesting that these narratives arise at all, because, during interviews, participants were not explicitly asked about negative experiences. Consequently, they were very personal and spontaneous parts of the subjects' memories. The codes that constitute this family are: Insecurity-fear, Sadness, and Disappointment (Figure A4).

\section{Discussion}

In an exercise of interpretation of three variables (Meanings of Nature, Benefits, and Sense of Place), it can be affirmed that leisure experiences in the selected WPA and their assessments are closely linked to the idea of Nature reflected in the "Meanings of Nature". Thus, the experiences reported are those that harmonize with the absence of human beings, the pristine, the divine origin, and feelings of peace and tranquility. As presented above, these are characterizations that correspond to a delimited sociocultural and historical view, in which certain places have been molded to meet these parameters [13].

In this way, other types of activities, contrary to the aforementioned notions, would be excluded and/or sanctioned within the WPA. This implies that Nature is not found as a reality prior to human 
action, but that it emerges from specific forms of relationship with the environment [71]. In other words, LEWPA contribute to articulate or generate Nature, conceptualized under specific socio-cultural and historical parameters. Without falling into a radical constructivism, such articulation or generation requires the fundamental participation of the environment and its other multiple creatures, in a more active or passive way. Thus, for example, the experience-articulation of Nature in a protected wilderness area can be very different in the eyes of the visitor if a fox decides to eat (human) garbage, than if it appears with wild prey in its mouth.

Another important aspect to discuss is the existence of families that can be considered central dimensions of the leisure experiences studied. In this way, we can propose the existence of a type of super-family in which categories that contain central aspects of the visit experience to a WPA are grouped together:

(1) The first is what we called "Transcendence" and considers the meaning of "Nature Sanctuary", the benefit "transcendent emotions", and the sense of place "Transcendence". These three families are associated with the quality of transcendence that emerges from the LEWPA. It emerges from participants' narratives of experiences in non-tangible spiritual planes and in some cases of connection with the divine, a creative force, and full integration with the natural world.

(2) The second super-family is "Perception of Well-being", constituted by the meaning of Nature "benefits"- physical and psychological benefits—and the sense of place "subjective well-being". This category reflects the centrality of the perception of well-being associated with the LEWPA, which in principle has a psychological emphasis and to a lesser extent relates the quality of restoration and physical toning attributed to the LEWPA. The predominant discourses of sensation of peace, tranquility, and perception of well-being emphasize the value assigned to the LEWPA as a provider of benefits that are not perceived in the everyday urban world.

(3) The third super-family is denominated as "Connection" and comprises the Meaning of Nature "connection", and the Sense of place "connection", and although in the case of the variable Benefits it did not emerge as a family of its own, it is present as a code in virtually all families of that variable. This super-family refers to the quality attributed to the LEWPA of generating, in the first place, a connection with Nature and, to a lesser extent, a connection with oneself and other people. It is considered as a central category and one of the most distinctive of the LEWPA, since it reveals the notion that the WPA embodies Nature in its purest state or in its essence. One of the most relevant aspects of the notion of "connection" is the idea of uniqueness or integration, that is, to feel part of Nature, to be one with the natural world, a feeling that seems only possible to perceive with this intensity in WPA. This could account for both the expectations regarding the experiences that one can have in places already defined as Nature reservoirs, as well as the type of disposition and activities carried out to maintain coherence with the former.

(4) Finally, the super-family "Environmental Awareness" is made up by the meaning of Nature "environmental awareness", the benefit "educational", and the sense of place "awareness". This category highlights the educational property of the LEWPA reflecting the generation of pro-environmental behavior and attitudes in the subjects of the study. Based on the experiences in WPA and their notions of Nature, people become aware of the deterioration that human beings have generated on the planet. It should be noted that the concrete structuring of WPA is already impregnated with an educational and prescriptive sense of taking "care of Nature". Thus, the mediation of various signs (e.g., "No campfires allowed", "Dispose of trash at recycling points", "Do not feed wild animals") and the presence of environmental education centers, as well as intentional verbal exchanges with Park Rangers, configure a kind of "moral geography" [72] (p. 130) of the place, which determines the visitors' cognitive, affective, and behavioral aspects. This family also highlights the double dimension of the educational experience, which is valued not only for the learning that is generated on a personal level, but also for the possibility of teaching others and making them aware of planetary deterioration. 


\section{Conclusions}

In addition to the identification of the notions of Nature, perceived benefits, and senses of the place mentioned, a first aspect to be highlighted in the conclusions is the close connection between these variables. This is not necessarily surprising because the three variables are articulated around the interests of the study subjects. What is interesting is the strength with which the romantic notion of Nature appears linked to the experiences reported and, consequently, with the benefits perceived and sense of place identified.

Another aspect to conclude is the evidence that LEWPA are considered as the generators of "benefits" and "sense of place". This is consistent with the literature that indicates that as a result of repeated and/or meaningful experiences in certain territories, affective, symbolic, and identity bonds can arise $[41,42,50,53]$. Thus, it seems necessary to develop studies that go into depth on how notions of Nature can be decisive in leisure experiences and in the sense of place for enthusiasts and non-enthusiasts of these kinds of practices.

Another conclusion that emerges from the discussion of the data and that is linked to the aforementioned factor is that, in the case of the LEWPA, sense of place can be considered as a final or second-order benefit. The connection that is generated between visitors and the WPA is perceived as a positive dimension and a desired change of setting. This point is of special interest if we accept the idea that a strong sense of place is a source of pro-environmental behavior and attitudes especially necessary in the current context of environmental crisis. For this reason, LEWPA, as generators of sense of place, can be conceived as a valid strategy to educate citizens that are aware of and committed to planetary survival. For this reason, we underline the responsibility of protected areas and the professionals who manage them when undertaking the environmental challenge of turning visits to WPA into meaningful leisure experiences, capable of stimulating the generation of senses of place. On the other hand, the results of this study could encourage conversations about the underlying conceptions of Nature both in the responsible state agencies and in their managers, in order to debate, for example, the type of activities and experiences that are offered to date in the WPA.

A final observation is related to the predominance of psychological and personal benefits that emerge from the analysis. This is consistent with the literature consulted [34]. However, we can conclude that, in this case, this is due to an aspect that should be studied in depth in other studies, since apparently the conception of Nature and in particular the experience of outdoor leisure predominant in international literature has underrated social interaction as a community value [73], underestimating its effect and valuation in WPA visitors. In this regard, it may be plausible that LEWPA, the perception of benefits, and sense of place may be more conditioned by cultural conceptions and practices such as those previously described, rather than by the scenery and various environmental elements preserved in the WPAA, which could be considered as less anthropocentric.

In relation to the limitations of the investigation, it is important to mention that the study is exploratory, because it opens new lines of research to better understand LEWPA, the benefits they provide (including a sense of place) and, above all, the role that the personal notion of Nature plays in shaping such leisure experiences.

This research aims to deepen our understanding of how notions of Nature can be decisive in leisure experiences and in the sense of place experienced by enthusiasts and non-enthusiasts for these kinds of activities. Future research should explore the perceived benefits and senses of place from LEWPA in towns where the predominant notion of Nature is not necessarily the romantic idea of it.

Author Contributions: Conceptualization, A.R., M.J.M., and P.B.; methodology, A.R., A.L.B., and S.C.; software, A.R. and A.L.B.; validation, A.R.; formal analysis, A.R., A.L.B., and S.C.; investigation, A.R., A.L.B., S.C., and R.S.; resources, R.S.; data curation, A.R.; writing-original draft preparation, A.R.; writing-review and editing, A.R.; visualization, A.R.; supervision, A.R.; project administration, A.R.; funding acquisition, A.R. All authors have read and agreed to the published version of the manuscript. 
Funding: This research was conducted within the framework of the project CONICYT-FONDECYT No 11150101, Chile and the program "Strengthening International Academic Networks" FRCAI_1729 of the Pontificia Universidad Católica de Chile.

Acknowledgments: In this section you can acknowledge any support given which is not covered by the author contribution or funding sections. This may include administrative and technical support, or donations in kind (e.g., materials used for experiments).

Conflicts of Interest: The authors declare no conflict of interest.

\section{Appendix A}

Table A1. Script of the interview.

\begin{tabular}{|c|c|c|}
\hline Question & Deepening Question & Variable to Analyze \\
\hline Your age? & & Sociodemographic \\
\hline Where do you live? & & Sociodemographic \\
\hline Where were you born? & & Sociodemographic \\
\hline Where did you grow up? & & Sociodemographic \\
\hline Do you know the limits of the XXXX National Park? & & Sense of place \\
\hline $\begin{array}{l}\text { Could you tell me what kind of practical activities you } \\
\text { usually do in the park / in your free time? }\end{array}$ & & Leisure activities \\
\hline $\begin{array}{l}\text { Is there anything that you find rewarding as a result of } \\
\text { these activities? }\end{array}$ & & Leisure benefits \\
\hline \multirow[t]{2}{*}{$\begin{array}{l}\text { Would you recommend this type of experience to your } \\
\text { friends or family? }\end{array}$} & Why? & Leisure benefits \\
\hline & $\begin{array}{l}\text { Do you share or have you shared } \\
\text { this hobby with others? } \\
\text { With whom? }\end{array}$ & Benefits of leisure / place bonding \\
\hline $\begin{array}{l}\text { Tell me how would you describe your relationship } \\
\text { with nature. }\end{array}$ & $\begin{array}{l}\text { Could you talk about what that } \\
\text { means nature to you? }\end{array}$ & Notion of Nature \\
\hline $\begin{array}{l}\text { In relation to your visit or visits to } X X X X \text { National Park. } \\
\text { Please describe three special places in this park (the } \\
\text { description can be made in relation to; the sights, smells, } \\
\text { sounds, animals, plants, ruins, buildings, etc.). }\end{array}$ & & Sense of place \\
\hline
\end{tabular}

\section{Appendix B}
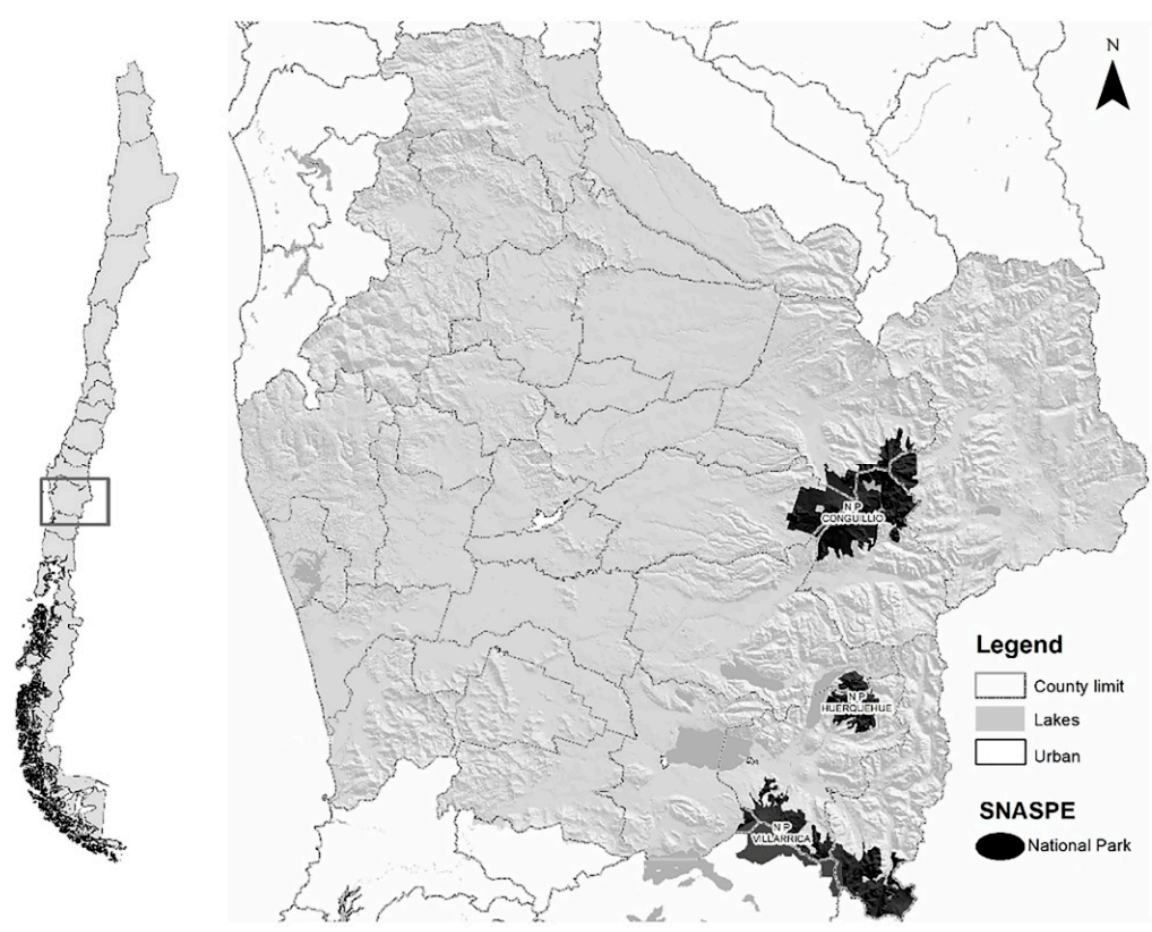

Figure A1. Location and distribution of the research's national parks. Source: own elaboration. 


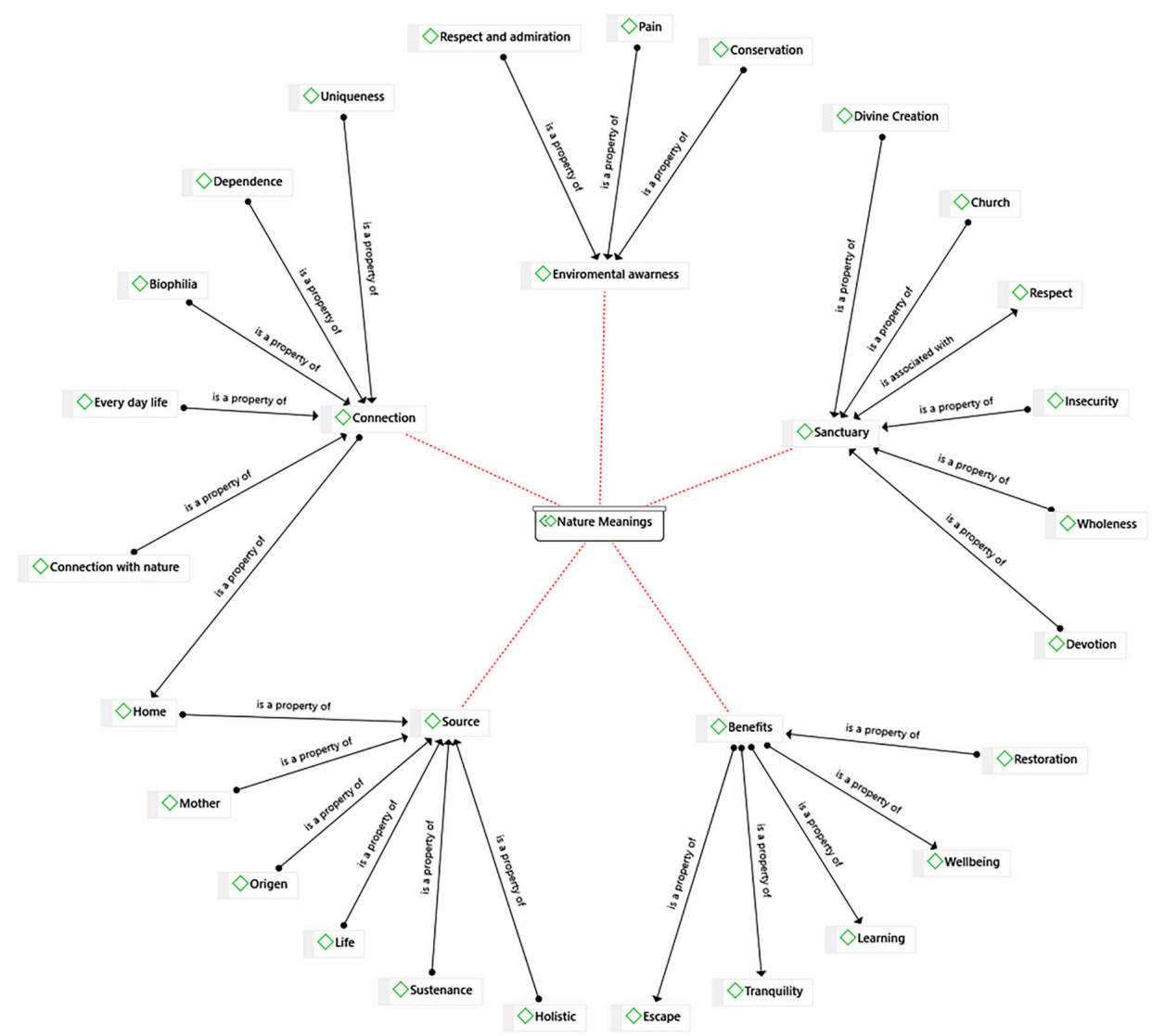

Figure A2. Hermeneutical map of meanings about Nature. Source: own elaboration.

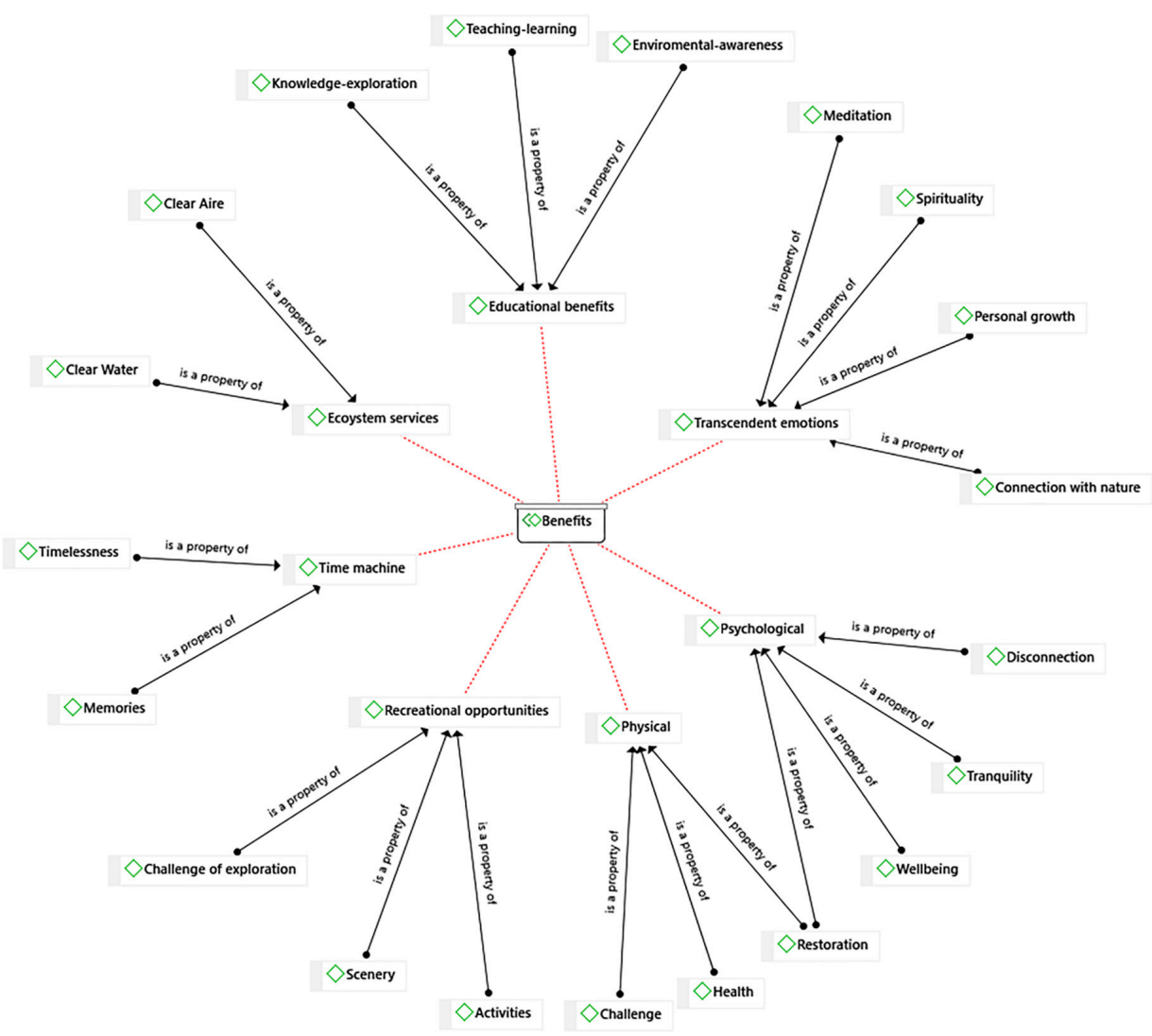

Figure A3. Hermeneutical map of benefits. Source: own elaboration. 


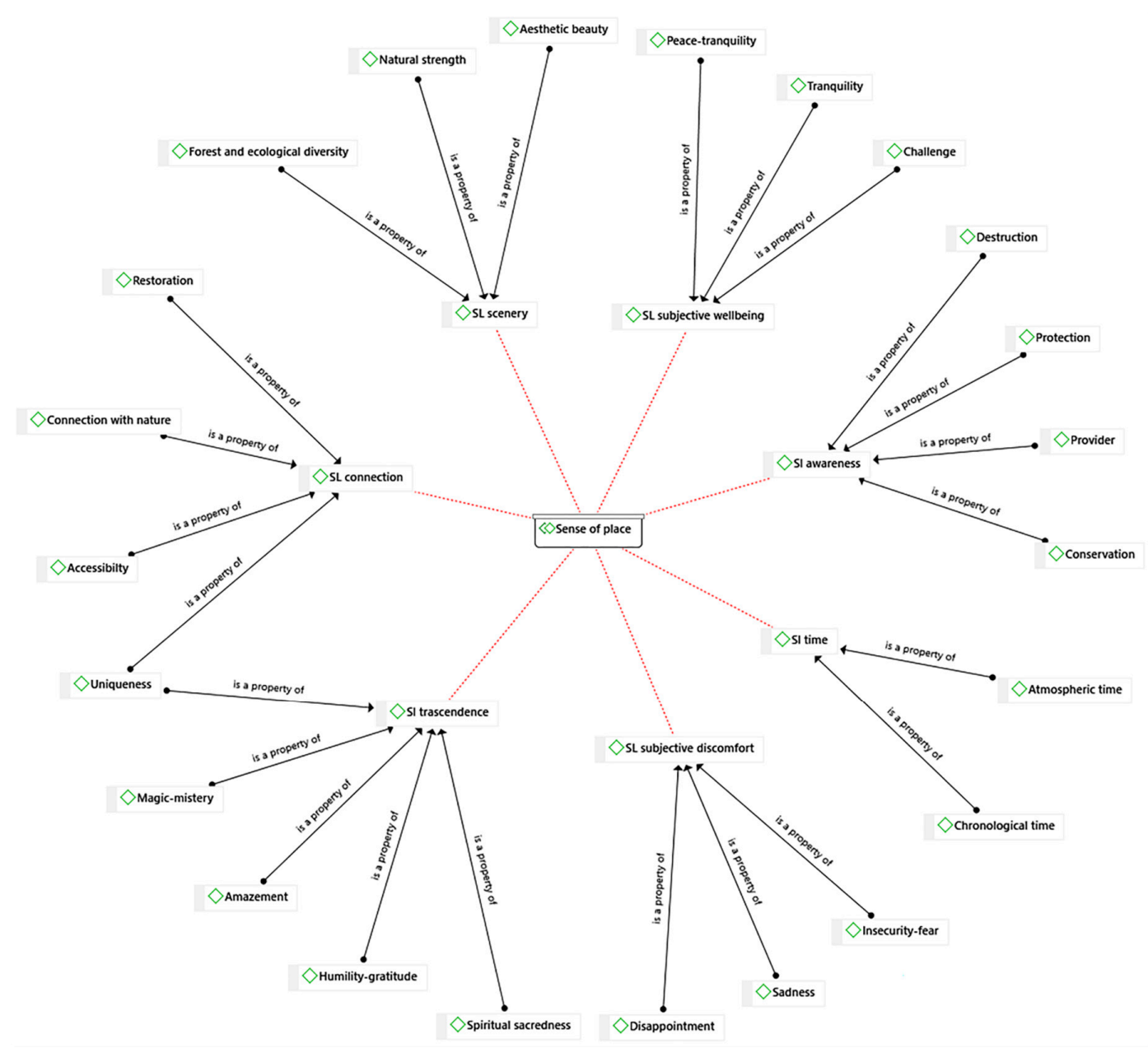

Figure A4. Hermeneutical map of sense of place. Source: own elaboration.

Table A2. Details of the study subjects.

\begin{tabular}{cccc}
\hline Profile & Villarrica & Huerquehue & Conguillio \\
\hline Resident who camps in the park & 4 & 3 & 2 \\
Resident who does not camp in the park & 7 & 3 & 1 \\
Non-resident who camps in the park & 0 & 4 & 3 \\
Non-resident who does not camp in the park & 2 & 3 & 4 \\
\hline
\end{tabular}

\section{References}

1. Ried, A. La experiencia de ocio al aire libre en contacto con la naturaleza, como vivencia restauradora de la relación ser humano-naturaleza. Polis 2015, 41, 11128.

2. Bahia, M. “Uma análise crítica das Atividades de Aventura: Possibilidades de uma Prática Consciente e Sustentável". In Dia a Dia Educacao; 2010. Available online: http://www.educadores.diaadia.pr.gov.br/ arquivos/File/2010/artigos_teses/EDUCACAO_FISICA/artigos/Bahia2.pdf (accessed on 19 December 2019).

3. Milton, K. Nature and the environment in indigenous and traditional cultures. In Spirit of the Environment. Religion, Value and Environmental Concern; Cooper, D., Palmer, J., Eds.; Routledge: London, UK, 1998; pp. 86-99.

4. Descola, P. Beyond Nature and Culture; The University of Chicago Press: London, UK, 2014.

5. Pálsson, G. Human-environmental relations: Orientalism, paternalism and communalism. In Nature and Society, Anthropological Perspectives; Descola, P., Pálsson, G., Eds.; Routledge: London, UK, 1996; pp. 63-81.

6. Ingold, T. Dreaming of dragons: On the imagination of real life. J. R. Anthropol. Inst. (N.S.) 2013, 19, 734-752. [CrossRef] 
7. Ellen, R. Introduction. In Redefining nature. Ecology, Culture and Domestication; Ellen, R., Fukui, K., Eds.; BERG: Oxford, UK, 1996; pp. 1-36.

8. Wulf, A. The invention of nature. In The Adventures of Alexander von Humboldt, the Lost Hero of Science; John Murray: London, UK, 2016.

9. West, P.; Igoe, J.; Brockington, D. Parks and peoples: The social impact of protected areas. Ann. Rev. Anthropol. 2006, 35, 251-277. [CrossRef]

10. Brockington, D.; Duffy, R.; Igoe, J. Nature Unbound, Conservation, Capitalism and the Future of Protected Areas; Earthscan: London, UK, 2008.

11. Strathern, M. No nature, no culture: The Hagen case. In Nature, Culture and Gender; MacCormack, C., Strathern, M., Eds.; Cambridge University Press: Cambridge, UK, 1980; pp. 174-222.

12. Pilgrim, S.; Pretty, J. Nature and culture: An introduction. In Nature and Culture; Pilgrim, S., Pretty, J., Eds.; Earthscan: London, UK, 2010.

13. Cronon, W. The trouble with wilderness; or, getting back to the wrong nature. In Uncommon Ground: Rethinking the Human Place in Nature; Cronon, W., Ed.; W. W. Norton; Co.: London, UK, 1996; pp. 69-90.

14. Driver, B.L.; Brown, P.J.; Peterson, G.L. Benefits of Leisure, State College; Venture Publishing: Champaign, IL, USA, 1991.

15. Foley, R.; Kistemann, T. Blue space geographies: Enabling health in place. Health Place 2015, 35, 1-9. [CrossRef]

16. Millennium Ecosystem Assessment. Ecosystems and human well-being. Ecosystems 2005, 5. [CrossRef]

17. Mitchell, R. Is physical activity in natural environments better for mental health than physical activity in other environments? Soc. Sci. Med. 2013, 92, 130-134. [CrossRef]

18. Ten Brink, P.; Mutafoglu, K.; Schweitzer, J.P.; Kettunen, M.; Twigger-Ross, C.; Kuipers, Y.; Emonts, M.; Tyrväinen, L.; Hujala, T.; Ojala, A. The Health and Social Benefits of Nature and Biodiversity protection, EXECUTIVE Summary. A Report of European Commission. (ENV.B.3/ETU/2014/0039); Institute for European Environmental Policy: London, UK, 2016.

19. Tinsley, H.E.A.; Tinsley, D.J. A theory of attributes, benefits and causes of leisure experience. Leis. Sci. 1996, 1, 1-45. [CrossRef]

20. Driver, B.L.; Bruns, D.H. Concepts and uses of benefits approach to leisure. In Leisure Studies: Prospects for the 21st Century State College; Jackson, E.L., Burton, T.L., Eds.; Venture Publishing: Champaign, IL, USA, 1999; pp. 349-369.

21. Horiuchi, M.; Endo, J.; Takayama, N.; Murase, N.; Nishiyama, N.; Saito, H.; Fujiwara, A. Impact of Viewing vs. Not Viewing a Real Forest on Physiological and Psychological Responses in the Same Setting. Int. J. Environ. Res. Public Health 2014, 11, 10883-10901. [CrossRef] [PubMed]

22. Park, B.; Tsunetsugu, Y.; Kasetani, T.; Kagawa, T.; Miyazaki, Y. The physiological effects of Shinrin-yoku (taking in the forest atmosphere or forest bathing): Evidence from field experiments in 24 forests across Japan. Environ. Health Prev. Med. 2010, 15, 18-26. [CrossRef]

23. Collado, S.; Corraliza, J.A. Conciencia ecológica y bienestar en la infancia. In Efectos de la Relación con la Naturaleza; CCS: Madrid, Spain, 2016.

24. Kaplan, R.; Kaplan, S. The Experience of Nature: A Psychological Perspective; Cambridge University Press: Cambridge, UK, 1989.

25. Tyrväinen, L.; Ojala, A.; Korpela, K.; Lanki, T. The influence of urban green environments on stress relief measures: A field experiment. J. Environ. Psychol. 2014, 38, 1-9. [CrossRef]

26. Ulrich, R.; Simons, R.; Losito, B. Stress recovery during exposure to natural and urban environments. J. Environ. Psychol. 1991, 11, 201-230. [CrossRef]

27. Zhang, J.W.; Piff, P.K.; Iyer, R.; Koleva, S.; Keltner, D. An occasion for unselfing: Beautiful nature leads to prosociality. J. Environ. Psychol. 2014, 37, 61-72. [CrossRef]

28. Heintzman, P. The spiritual benefits of leisure. Leisure/Loisir 2009, 33, 419-445. [CrossRef]

29. Chawla, L. Benefits of Nature Contact for Children. J. Plan. Lit. 2015, 30, 433-452. [CrossRef]

30. Van den Berg, M.; Wendel-Vos, W.; Van Poppel, M.; Kemper, H.; Van Mechelen, W.; Maas, J. Health benefits of green spaces in the living environment: A systematic review of epidemiological studies. Urban For. Urban Green. 2015, 14, 806-816. [CrossRef]

31. De Bell, S.; Graham, H.; Jarvis, S.; White, P. The importance of nature in mediating social and psychological benefits associated with visits to freshwater blue space. Landsc. Urban Plan. 2017, 167, 118-127. [CrossRef] 
32. Schebella, M.F.; Weber, D.; Lindsey, K.; Daniels, C.B. For the Love of Nature: Exploring the Importance of Species Diversity and Micro-Variables Associated with Favorite Outdoor Places. Front. Psychol. 2017, 8. [CrossRef]

33. Williams, K.; Harvey, D. Transcendent experience in forest environments. J. Environ. Psychol. 2001, 21, 249-260. [CrossRef]

34. Dallimer, M.; Irvine, K.N.; Skinner, A.M.; Davies, Z.G.; Rouquette, J.R.; Maltby, L.L.; Warren, P.H.; Armsworth, P.R.; Gaston, K.J. Gaston, Biodiversity and the Feel-Good Factor: Understanding Associations between Self-Reported Human Well-being and Species Richness. BioScience 2012, 62, 47-55. [CrossRef]

35. Hartig, T.; Mitchell, R.; de Vries, S.; Frumkin, H. Nature and health. Annu. Rev. Public Health 2014, 35, 207-228. [CrossRef]

36. Wheeler, B.W.; Lovell, R.; Higgins, S.L.; White, M.P.; Alcock, I.; Osborne, N.J. Beyond greenspace: An ecological study of population general health and indicators of natural environment type and quality. Int. J. Health Geographic's 2015, 14, 17. [CrossRef] [PubMed]

37. De Vries, S.; Have, M.; van Dorsselaer, S.; van Wezep, M.; Hermans, T.; de Graaf, R. Local availability of green and blue space and prevalence of common mental disorders in the Netherlands. Br. J. Psychiatry Open 2016, 2, 366-372. [CrossRef] [PubMed]

38. Triguero-Mas, M.; Dadvand, P.; Cirach, M.; Martínez, D.; Medina, A.; Mompart, A. Natural outdoor environments and mental and physical health: Relationships and mechanisms. Environ. Int. 2015, 77, 35-41. [CrossRef] [PubMed]

39. Altman, I.; Low, S.M. Place Attachment: A Conceptual Inquiry. Place Attach. 1992, 1-12. [CrossRef]

40. Manzo, L.; Devine-Wright, P. Place Attachment: Advances in Theory, Methods and Applications; Routledge: London, UK, 2014.

41. Relph, E. Place and Placelessness; University of Toronto: Toronto, ON, Canada, 1976.

42. Ried, A.; Le Bon, A.; Carmody, S.; Santos, R. Sentidos del lugar desde la experiencia de ocio y turismo en áreas silvestres protegidas: Una metasíntesis. PASOS. Rev. Tur. Patrim. Cult. 2018, 16, 701-716. [CrossRef]

43. Altman, I.; Low, S.M. Place Attachment; Springer: Boston, MA, USA, 1992.

44. Eisenhauer, B.; Krannich, R.; Blahna, D. Attachments to Special Places on Public Lands: An Analysis of Activities, Reason for Attachments, and Community Connections Society. Nat. Resour. Int. J. 2000, 13. [CrossRef]

45. Kyle, G.; Chick, G. The Social Construction of a Sense of Place. Leis. Sci. 2007, 29, 209-225. [CrossRef]

46. Budruk, M.; Stanis, S.A.W. Place attachment and recreation experience preference: A further exploration of the relationship. J. Outdoor Recreat. Tour. 2013, 1-2, 51-61. [CrossRef]

47. Campelo, A.; Aitken, R.; Thyne, M.; Gnoth, J. Sense of Place: The Importance for Destination Branding. J. Travel Res. 2013, 53, 154-166. [CrossRef]

48. Wynveen, C.J.; Kyle, G.T.; Absher, J.D.; Theodori, G.L. The Meanings Associated with Varying Degrees of Attachment to a Natural Landscape. J. Leis. Res. 2011, 43, 290-311. [CrossRef]

49. Stokowski, P.A. Languages of place and discourses of power: Constructing new senses of place. J. Leis. Res. 2002, 34, 368-382. [CrossRef]

50. Wynveen, C.J.; Kyle, G.T.; Sutton, S.G. Place Meanings Ascribed to Marine Settings: The Case of the Great Barrier Reef Marine Park. Leis. Sci. 2010, 32, 270-287. [CrossRef]

51. Young, M. The Social Construction of Tourist Places. Aust. Geogr. 1999, 30, 373-389. [CrossRef]

52. Seamon, D.; Sowers, J. Place and Placelessness, Edward Relph. Hum. Geogr. 2008, 43-51. [CrossRef]

53. Tuan, Y. Topofilia (1a); Columbia University Press: New York, NY, USA, 1974.

54. Cresswell, T. Space and Place (1977): Yi-Fu Tuan. In Key Texts in Human Geography; Hubbard, P., Kitchin, R., Valentine, G., Eds.; 2008; pp. 53-61. Available online: http://0-knowledge.sagepub.com.oasis.unisa.ac.za/ view/key-texts-in-human-geography/SAGE.xml (accessed on 16 December 2019).

55. Davenport, M.; Anderson, D. Getting From Sense of Place to Place-Based Management: An Interpretive Investigation of Place Meanings and Perceptions of Landscape Change. Soc. Nat. Resour. 2005, 18, 625-641. [CrossRef]

56. Kianicka, S.; Buchecker, M.; Hunziker, M.; Müller-Böker, U. Locals' and Tourists' Sense of Place. Mt. Res. Dev. 2006, 26, 55-63. [CrossRef]

57. Korpela, K.; Borodulin, K.; Neuvonen, M.; Paronen, O.; Tyrväinen, L. Analyzing the mediators between nature-based outdoor recreation and emotional well-being. J. Environ. Psychol. 2014, 37, 1-7. [CrossRef] 
58. Newell, P.B. A Cross-Cultural Examination of Favorite Places. Environ. Behav. 1997, 29, 495-514. [CrossRef]

59. Roggenbuck, J.W.; Driver, B.L. Benefits of non-facilitated uses of wilderness. Scientist 2000, 3, $33-49$.

60. Fish, R.; Church, A.; Winter, M. Conceptualising cultural ecosystem services: A novel framework for research and critical engagement. Ecosyst. Serv. 2016, 21, 208-217. [CrossRef]

61. Small, N.; Munday, M.; Durance, I. The challenge of valuing ecosystem services that have no material benefits. Glob. Environ. Chang. 2017, 44, 57-67. [CrossRef]

62. Williams, D.R.; Patterson, M.E.; Roggenbuck, J.W.; Watson, A.E. Beyond the commodity metaphor: Examining emotional and symbolic attachment to place. Leis. Sci. 1992, 14, 29-46. [CrossRef]

63. Henderson, K.A. Dimensions of Choice: Qualitative Approaches to Parks, Recreation, Tourism, Sport, and Leisure Research, 2nd ed.; Palo Alto: Santa Clara, CA, USA, 2006.

64. Patterson, M.E.; Watson, A.E.; Williams, D.R.; Roggenbuck, J.R. An Hermeneutic Approach to Studying the Nature of Wilderness Experiences. J. Leis. Res. 1998, 30, 423-452. [CrossRef]

65. Schroeder, H.W. Ecology of the heart: Understanding how people experience natural environments. Nat. Resour. Manag. Hum. Dimens. 1996, 13, 27.

66. Amsden, B.L.; Stedman, R.C.; Kruger, L.E.; Anderson, D.H.; Fulton, D.C.; Approaches, G.; Theodori, G.L. The Meanings Associated with Varying Degrees of Attachment to a Natural Landscape. Leis. Sci. 2013, 28, 155-163. [CrossRef]

67. Patterson, M.; Williams, D. Collecting and Analyzing Qualitative Data: Hermeneutic Principles, Methods, and Case Examples; Venture: Champaign, IL, USA, 2002; pp. 1-129.

68. Champ, J.G.; Williams, D.R.; Knotek, K. Wildland Fire and Organic Discourse: Negotiating Place and Leisure Identity in a Changing Wildland Urban Interface. Leis. Sci. 2009, 31, 237-254. [CrossRef]

69. Glaser, B.G.; Strauss, A.L. The discovery of grounded theory. Int. J. Qual. Methods 1967, 5, 1-10. [CrossRef]

70. Taylor, S.J.; Bogdan, R. Introducción a los Métodos Cualitativos; Paidos, Ed.; 2000. Available online: https://asodea. files.wordpress.com/2009/09/taylor-s-j-bogdan-r-metodologia-cualitativa.pdf (accessed on 16 December 2019).

71. Ingold, T. The Perception of the Environment: Essays on Livelihood, Dwelling and Skill; Routledge: London, UK, 2000.

72. Matless, D. Moral geography in Broadland. Ecumene 1994, 1, 127-155. [CrossRef]

73. Ryan, S. Theorizing Outdoor Recreation and Ecology; Springer: Berlin/Heidelberg, Germany, 2015.

(C) 2020 by the authors. Licensee MDPI, Basel, Switzerland. This article is an open access article distributed under the terms and conditions of the Creative Commons Attribution (CC BY) license (http://creativecommons.org/licenses/by/4.0/). 